\title{
Effects of particle size of ground alfalfa hay on caecal bacteria and archaea populations of rabbits
}

\author{
Mei Yuan ${ }^{1}$, Siqiang Liu ${ }^{1}$, Zhisheng Wang ${ }^{1}$, Lizhi Wang $^{1}$, Bai Xue $^{1}$, Huawei Zou ${ }^{1}$, Gang Tian $^{1}{ }^{1}$ Jingyi Cai $^{1}$, \\ Quanhui Peng ${ }^{\text {Corresp. } 1}$ \\ ${ }^{1}$ Animal Nutrition Institute, Key Laboratory of Bovine Low-Carbon Farming and Safety Production, Sichuan Agricultural University, Chengdu, China \\ Corresponding Author: Quanhui Peng \\ Email address: pengquanhui@126.com
}

This work was aimed to investigate the effects of the different particle size of ground alfalfa hay on caecal microbial and archeal communities of rabbits. One hundred-twenty New Zealand rabbits $(950.3 \pm 8.82 \mathrm{~g})$ were allocated into four treatments, with 5 replicates in each treatment and 6 rabbits in each replicate. The particle sizes of the alfalfa meal in the four treatment diets were $2500,1000,100$ and $10 \mu \mathrm{m}$ respectively, while the other ingredients were ground through a $2.5 \mathrm{~mm}$ sieve. High-throughput sequencing technology was applied to examine the differences in bacteria and methanogenic archaea diversity in the caecum of the four treatment groups of rabbits. A total of 745,946 bacterial sequences (a mean of 31,081 \pm 13901 sequences per sample) and 539,227 archaeal sequences (a mean of $22,468 \pm 2443$ sequences per sample) were recovered from twenty-four caecal samples, and were clustered into 9,953 and 2,246 OTUs respectively. A total of 26 bacterial phyla with 465 genera and 3 archaeal phyla with 10 genera were identified after taxonomic summarization. Bioinformatic analyses illustrated that Firmicutes $(58.69 \%$ $68.50 \%)$ and Bacteroidetes $(23.96 \%$ 36.05\%) were the two most predominant bacterial phyla and Euryarchaeota (over 99.9\%) was the most predominant archaeal phyla in the caecum of all rabbits. At genus level, as the particle size of alfalfa decreased from 2500 to $10 \mu \mathrm{m}$, the relative abundances of Ruminococcaceae UCG-014 $(P<0.001)$ and Lactobacillus ( $P=0.043$ ) were increased and Ruminococcaceae UCG-005 ( $P=0.012$ ) was increased first and then decreased when the alfalfa particle size decreased, while Lachnospiraceae NK4A136 group $(P=0.016)$, Ruminococcaceae NK4A214 $(P=0.044)$, Christensenellaceae $R-7$ group $(P=0.019)$, Lachnospiraceae other (Family) $(P=0.011)$ and Ruminococcaceae UCG-013 ( $P=0.021)$ were decreased. The relative abundance of Methanobrevibacter was increased from $62.48 \%$ to $90.40 \%(P<0.001)$, whereas the relative abundance of Methanosphaera was reduced from $35.47 \%$ to $8.62 \%(P<0.001)$. In conclusion, as the particle size of alfalfa meal decreased, both the bacterial and archaeal population in the caecum of rabbit experienced alterations, however archaea response 
earlier than bacteria to the decrease of alfalfa meal particle size. 
1 Effects of particle size of ground alfalfa hay on caecal bacteria and archaea populations of 2 rabbits

3 Mei Yuan, Siqiang Liu, Zhisheng Wang, Lizhi Wang, Bai Xue, Huawei Zou, Gang Tian, Jingyi

4 Cai, Quanhui Peng*

5 Animal Nutrition Institute, Key Laboratory of Bovine Low-Carbon Farming and Safety

6 Production, Sichuan Agricultural University, Chengdu, China.

7 * Corresponding author E-mail: pengquanhui@126.com

8

9 Acknowledgements

10 The financial support was provided by the National Natural Science Foundation of China

11 (31402104).

12

13

14

15

16

17

18

19

Peer] reviewing PDF | (2019:02:35028:3:0:NEW 1 Sep 2019) 


\section{ABSTRACT}

This work was aimed to investigate the effects of the different particle size of ground alfalfa hay on caecal microbial and archeal communities of rabbits. One hundred-twenty New Zealand rabbits $(950.3 \pm 8.82 \mathrm{~g})$ were allocated into four treatments, with 5 replicates in each treatment and 6 rabbits in each replicate. The particle sizes of the alfalfa meal in the four treatment diets were $2500,1000,100$ and $10 \mu \mathrm{m}$ respectively, while the other ingredients were ground through a $2.5 \mathrm{~mm}$ sieve. High-throughput sequencing technology was applied to examine the differences in bacteria and methanogenic archaea diversity in the caecum of the four treatment groups of rabbits. A total of 745,946 bacterial sequences (a mean of 31,081 \pm 13901 sequences per sample) and 539,227 archaeal sequences (a mean of 22,468 \pm 2443 sequences per sample) were recovered from twenty-four caecal samples, and were clustered into 9,953 and 2,246 OTUs respectively. A total of 26 bacterial phyla with 465 genera and 3 archaeal phyla with 10 genera were identified after taxonomic summarization. Bioinformatic analyses illustrated that Firmicutes $(58.69 \% \sim 68.50 \%)$ and Bacteroidetes $(23.96 \% \sim 36.05 \%)$ were the two most predominant bacterial phyla and Euryarchaeota (over 99.9\%) was the most predominant archaeal phyla in the caecum of all rabbits. At genus level, as the particle size of alfalfa decreased from 2500 to $10 \mu \mathrm{m}$, the relative abundances of Ruminococcaceae UCG-014 $(P<0.001)$ and Lactobacillus $(P=0.043)$ were increased and Ruminococcaceae UCG-005 $(P=0.012)$ was increased first and then decreased when the alfalfa particle size decreased, while Lachnospiraceae NK4A136 group $(P=0.016)$, Ruminococcaceae NK4A214 $(P=0.044)$, Christensenellaceae R-7 group $(P=0.019)$, Lachnospiraceae other (Family) $(P=0.011)$ and Ruminococcaceae UCG-013 ( $P=0.021)$ were decreased. The relative abundance of Methanobrevibacter was increased from $62.48 \%$ to $90.40 \%(P<0.001)$, whereas the relative abundance of Methanosphaera was reduced from $35.47 \%$ to $8.62 \%(P<0.001)$. In conclusion, as the particle size of alfalfa meal decreased, both the bacterial and archaeal population in the caecum of rabbit experienced alterations, however archaea response earlier than bacteria to the decrease of alfalfa meal particle size. 
55

56

57

58

59

60

61

62

63

64

65

66

67

Key words: Rabbits, Caecum, Fiber particle size, Bacteria, Archaea

\section{INTRODUCTION}

8

Rabbit meat is an important part of meat products in China. According to FAO official database FAOSTA (http://faostat.fao.org/), the output of Chinese rabbit meat was $7.27 \times 10^{5} \mathrm{t}$ and the per capita consumption was $0.527 \mathrm{~kg}$ in 2013. In recent years, the rabbit breeding industry has also prospered, and more and more attention has been paid to rabbit research. Rabbit is a monogastric herbivore animal that has a certain ability to digest fiber. Although the digestibility is not as high as other herbivores (Voris et al., 1940; Slade et al., 1969), plant fiber has special nutritional and physiological functions in rabbits (Chiou et al., 1994; Cheeke, 1987; Jenkins, 1999). Undoubtedly, dietary fiber is the most important component in the diet of rabbits, especially, alfalfa as a balanced source of fiber is a good choice for rabbit feed (García et al., 1995; García et al., 1995). Rabbits possess very developed caecum, accounting for about 40\% capacity of the gastrointestinal tract (Jenkins, 1999). The fiber in the diet of rabbit is mainly degraded by caecal microorganisms such as bacteria, fungi, archaea, etc. The species, quantity and balance of intestinal microorganisms are important indicators of the health of animals, and are also important manifestations of function of digestive tract (Nicholson et al., 2012; Jami et al., 2013). Thus, it is very important to maintain the stable structure of the intestinal microorganisms in rabbits for the digestion and absorption of nutrients and intestinal health.

The intestinal microorganism is always in the dynamic change, and there are many factors affect the composition of the gut microbiota, especially fiber plays an important role in the balance of intestinal microflora structure. Previous work (García et al., 2000; Chang et al., 2006) showed that different fiber sources had effects on the caecel microorganism fermentation activity in rabbits. Cao et al. (2016) also suggested that fiber source will change the methanogenic 
80

81

community in the hindgut of pigs. Whereas the fiber level has controversial effects on the changes of caecal microorganism in rabbits. Boulharouf et al. (1991) showed that when dietary fiber level increased, the number of bacteria decomposing fibers in caecum of rabbits increased. On the contrary, Bennegadi et al. (2003) showed that decreased dietary fiber levels reduced the proportion of archaea community but increased the number of Bacteroidetes and Ruminococcus albus (both bacteria can break down the fiber) in the caecum of rabbits. Physical structure, especially particle size, is another important characteristic of fiber that influences caecal microorganism in rabbits. García et al. (2000) reported that the feed particle size has a significant effect on caecum microorganism fermentation in rabbits, however, specific studies on changes in microbial composition and structure are scarce.

In addition, most of the existing reports about particle size of diet fiber in rabbits are descriptions on the retention time of chyme in the caecum, the digestion of nutrients and the growth performance (Gidenne et al., 1991; Gidenne, 1993; Nicodemus et al., 2010; Romero et al., 2011). Yet limited studies on the effects of fiber particle size on caecal microbial composition in rabbits exist, let alone comparison of the sensitivity of bacteria and archaea to the diet fiber particle size. Therefore, the objective of this study was to explore the effects of different alfalfa hay particle size on the composition and response of caecum bacteria and archaea in rabbits using Illumina sequencing technology.

\section{MATERIALS AND METHODS}

The experimental protocol used in the present study was approved by the Animal Policy and Welfare Committee of the Agricultural Research Organization of Sichuan Province, China, and was in accordance with the guidelines of the Animal Care and Ethical Committee of the Sichuan Agricultural University (Permission code SYXK (chuan) 2014-187). 
Animal experiment and sample collection

107

A total of 120 New Zealand rabbits (half male and female) with average body weight (950.3 109 $\pm 8.82 \mathrm{~g}$ ), weaned at 35 days of age were selected and allocated into 4 treatments, with 5 replicates in each treatment and 6 rabbits in each replicate, and the rabbits were kept in 3 pairs with 2 rabbits per cage. Rabbits were housed in the same building (Sichuan Agricultural University, China) in flat-deck cages $(600 \times 250 \times 330 \mathrm{~mm})$ for the $49 \mathrm{~d}$ experiment. The temperature inside the house was maintained at $15-25^{\circ} \mathrm{C}$ and rabbits had ad libitum access to water and diets during the whole experimental period. Neither feed nor drinking water was medicated with antibiotics, but a coccidiostatic (robenidine) was provided in the feed. In this study, the diets (Table S1) were formulated according to NRC (1977) Growing Rabbit Feeding Standards, and the alfalfa meal incorporated into the four diets were 2500, 1000, 100 and $10 \mu \mathrm{m}$, respectively. Firstly, alfalfa meal with particle sizes of $2500,1000,100$ and $10 \mu \mathrm{m}$ were produced, and then the rest of the ingredients were milled through a $2.5-\mathrm{mm}$ grinder screen. After all the ingredients were ready, they were mixed and granulated (diameter was $3 \mathrm{~mm}$ ). After the finish of the growth experiment, 24 animals were slaughtered (6 rabbits per diet) by cervical dislocation $1 \mathrm{~h}$ before dark (19:00) to avoid soft feces excretion. Once slaughtered, $50 \mathrm{~g}$ of cecal content was collected in sterile conditions. The samples were immediately frozen at $-80{ }^{\circ} \mathrm{C}$ until DNA extraction.

DNA extraction 
129

130

131

132

133

134

135

136

137

138

139

140

141

142

143

144

145

146

147

148

149

150

151

152

153

154

9

process. According to the manufacturer's instructions, total genomic DNA was extracted from caecal samples using a DNeasy PowerSoil Kit (Qiagen, Valencia, CA, USA) that included a step of the microbiological cells to be mechanically broken. The quality and concentration of the extracted DNA was detected, respectively, using $0.8 \%$ agarose gel electrophoresis and a NanoDrop ND-1000 spectrophotometer (Nyxor Pharmacia, Paris, France). All extracted DNA samples were diluted to $10 \mathrm{ng} / \mu \mathrm{L}$ using sterile ultrapure water and stored at $-20{ }^{\circ} \mathrm{C}$ until used for real-time PCR and Illumina sequence analyses.

\section{PCR amplification, Illumina library generation and sequencing}

8

The V4 variable region of 16S rRNA gene was amplified by using caecal total DNA as template. Selecting 515F (5'-GTGCCACMCCGCGGTAA-3') and 806R (5'GGACTACHVGGGTWTCTAAT-3') as the primer pair for the bacteria (Caporaso et al., 2011), while selecting A516F (5'-TGYCAGCCGCCGCGGTAAHACCVGC-3') and U806R (5'GGACTACHVGGGTWTCTAAT-3') as the primer pair for the archaea (Kuroda et al., 2015). 16S rRNA genes were amplified using the specific primer with $12 \mathrm{nt}$ unique barcode, and used the same reaction system for PCR amplification for bacteria and archaea. The total PCR mixture (25 $\mu \mathrm{L}$ ) contained $1 \times$ PCR buffer, $1.5 \mathrm{mM} \mathrm{MgCl}_{2}$, each deoxynucleoside triphosphate at $0.4 \mu \mathrm{M}$, each primer at $1.0 \mu \mathrm{M}, 0.5 \mathrm{U}$ of KOD-Plus-Neo (Toyobo, Tokyo, Japan) and $10 \mathrm{ng}$ template DNA. The PCR amplification program consists of initial denaturation at $94{ }^{\circ} \mathrm{C}$ for $1 \mathrm{~min}$, followed by 30 cycles of denaturation at $94{ }^{\circ} \mathrm{C}$ for $20 \mathrm{~s}$, annealing at $54{ }^{\circ} \mathrm{C}$ for $30 \mathrm{~s}$, elongation at $72{ }^{\circ} \mathrm{C}$ for $30 \mathrm{~s}$, and a final extension at $72{ }^{\circ} \mathrm{C}$ for $5 \mathrm{~min}$. Three replicates of PCR reactions for each sample were combined together, PCR products mixed with 1/6 volume of $6 \mathrm{X}$ loading buffer were loaded on $2 \%$ agarose gel for detection. And we used a 2 step process for library preparation. First, 16S amplicons were generated using PCR to generate 200-400bp amplicons. Second, we added unique barcodes to samples using emulsion PCR (EmPCR) to prevent chimera 
155

156

157

158

159

160

161

162

163

164

165

166

167

168

169

170

171

172

173

174

175

176

177

178

179

180

4

775

formation (Williams et al., 2006), and the PCR was stopped at linear stage. This methodological basic principle is dilution and compartmentalization of template molecules in water droplets in a water-in-oil emulsion. Ideally, the dilution is to a degree where each droplet contains a single template molecule and functions as a micro-PCR reactor (Rashmi, 2016). This method enables reduces the formation of artifactual molecules, as often seen in conventional PCR, thus preserving library complexity (Williams et al., 2006; Qiu et al., 2001). The electrophoresis band was purified using OMEGA Gel Extraction Kit (Omega Bio-Tek, USA), the gel purified barcoded amplicons were pooled with equal molar amount and quantified on a Qubit@ 2.0 Fluorometer (Thermo Scientific). Finally, 15\% of PhiX control library was spiked into the amplicon pool to improve the unbalanced and biased base composition. In brief, sequencing libraries were generated using TruSeq DNA PCR-Free Sample Prep Kit following manufacturer's recommendations and index codes were added, and using ZymoBIOMICS Microbial Community Standard (Cat\#D6300) as the positive control. The library quality was assessed on the Qubit@2.0 Fluorometer (Thermo Scientific) and Agilent Bioanalyzer 2100 system. At last, the library was applied to paired-end sequencing $(2 \times 250 \mathrm{bp})$ with the Hiseq Illumina Sequencing Platform (Rhonin Biosciences Co., Ltd, Chengdu, China), according to the protocols described by Caporaso et al. (2012).

\section{Bioinformatics analysis}

The sequences were analyzed according to Usearch (version $7.1 \mathrm{http}: / /$ drive5.com/uparse/) and QIIME (Caporaso et al., 2010) pipeline. Paired-end reads from the original DNA fragments were merged using FLASH (Magoč and Salzberg, 2011). Then sequences were assigned to each sample according to the unique barcode. The first step was to filter low quality reads (length $<$ $200 \mathrm{bp}$, more than two ambiguous base 'N', or average base quality score < 30) and truncated sequences where quality scores decay (score < 11) using Trimmomatic (Bolger et al., 2014) and 
181

182

183

184

185

186

187

188

189

190

191

192

193

194

195

196

197

198

199

200

201

202

203

204

205 3

Usearch. After finding duplicated sequences, discarded all the singletons, which may be sequencing errors (http://www.drive5.com/usearch/manual/singletons.html) and lead to false positive results for overestimation of diversity. Sequences were clustered into operational taxonomic units (OTUs) at 97\% identity threshold using UPARSE algorithms (Edgar, 2013), and picked representative sequences and removed potential chimeras using Uchime algorithm (Edgar et al., 2011). Taxonomy were assigned using the Silva (http://www.arb-silva.de/) database (Quast et al., 2013) and uclust classifier in QIIME (version 1.8.0). Representative sequences were aligned using PyNAST (Caporaso et al., 2010) embedded in QIIME. After quality checking, phylogenetic trees were reconstructed based on maximum likelihood-approximation method using the generalised time-reversible (GTR) model in FastTree (Price et al., 2010).

Then the filtered OTU is removed from the OTU table in the process of evolutionary tree reconstruction, and the OTU table is resampled so that each sample has the same sequence number. Phylogenetic diversity (Faith's PD18) was calculated using Picante (Kembel et al., 2010). Weighted and Unweighted Unifrac distances were calculated in GUniFrac version 1.1 (Chen, 2012). The analysis of alpha and beta diversity metrics was conducted with Vegan (version 2.0-2. R CRAN package). Rarefaction curves were generated based on these three metrics. Principal component analysis (PCA) was applied to reduce the dimensions of original community data. Hierarchical cluster analysis was done using R (https://www.R-project.org/) function hclust. To identify if there were significant differences among different groups, permutational multivariate analysis of variance was performed based on the dissimilarity matrix.

\section{Statistical analysis}

The effects of alfalfa meal particle size on cecal microbial communities were analyzed using the MIXED procedure of SAS v9.4 (SAS Institute Inc., Cary, NC, USA). The model used 
206 for the analysis was

207

208

209

210

211

212

213

214

215

216

217

218

219

220

221

222

223

224

225

226

227

228

229

\section{RESULTS}

$$
\mathrm{Y}_{\mathrm{ij}}=\mu+\mathrm{T}_{\mathrm{i}}+\mathrm{e}_{\mathrm{ij}}
$$

where $Y_{i j}$ is an observation on the dependent variable $i j, \mu$ is the overall population mean, $T_{i}$ is the fixed effect of alfalfa meal particle size, and $\mathrm{e}_{\mathrm{ij}}$ is the random error associated with the observation ij. Tukey-Kramer multiple comparison tests were performed after differences were detected. Differences between means with $P<0.05$ were accepted as statistically significant differences.

\section{Sequencing depth, coverage and alpha diversity}

A rarefaction test was performed at the OTU level and the results are presented (Fig. S1). As can be seen from the rarefaction curve that all of the samples tended to reach a plateau, indicating that the sequencing quantity of both bacteria and archaea covered most microorganisms. Measures of alpha diversity were shown in Table 1. As for the bacteria, the OTUs, Chao1 index, Shannon-Wiener index and PD value (phylogenetic diversity) were all numerically higher in group $10 \mu \mathrm{m}$ than that of the other three groups $(P>0.05)$. As for the archaea, the Shannon-Wiener index of group 1000, 100 and $10 \mu \mathrm{m}$ were significantly decreased compared with group $2500 \mu \mathrm{m}(P=0.044)$. However, no significant difference was obtained among 1000, 100 and $10 \mu \mathrm{m}$ groups. Above results suggested that rabbit caecum alpha diversity of bacteria and archaea experienced different alterations when the alfalfa particle size decreased.

A total of 745,946 bacterial sequences were generated after quality control with a mean of $31,081 \pm 13901$ (mean \pm standard deviation $[\mathrm{SD}], \mathrm{n}=24)$ per sample, and the mean length of tag 
230

231

232

233

234

235

236

237

238

239

240

241

242

243

244

245

246

247

248

249

250

251

252

253

254

255

2

N50 is $304 \pm 6$ base pairs (bp). Based on the principle that the similarity is greater than $97 \%$, the obtained effective sequences were clustered into a total of 9,953 OTUs, the average OTU was $1,896 \pm 251($ mean $\pm \mathrm{SD}, \mathrm{n}=24)$ per sample. A total of 2107 OTUs were shared in all of four treatments, while 1390, 587, 632 and 1791 OTUs were exclusively found in group 2500, 1000, 100 and $10 \mu \mathrm{m}$, respectively (Fig. 1A). Illumina HiSeq sequence of the archaeal 16S rRNA yielded 539,227 sequences for the 24 caecal samples, with a mean of 22,468 \pm 2443 sequences per sample, and the mean length of tag N50 is $292 \pm 4$. A total of 2246 OTUs were assigned, and each sample contained $336 \pm 21$ OTUs. Furthermore, 351 OTUs were shared by the four groups, while 404, 391, 378 and 398 OTUs were exclusively found in group 2500, 1000, 100 and $10 \mu \mathrm{m}$, respectively (Fig. 1B).

\section{Analysis of microbial community similarity in caecum of rabbits}

Community OTU comparisons were visualised by clustering analysis (OTU $\geq 97 \%$ identity, species level similarity) using weighted unifrac clustering in Fig. 2. The closer samples and the shorter branches are indicating the more similar the species composition of the two samples. The relationship of bacterial community between different treatments showed that the samples were clustered into three branches (Fig. 2A). All samples in $10 \mu \mathrm{m}$ group clustered into the same clade, however, sample 2500-2, 2500-4 and 100-3 were clustered into this clade. The samples of group 2500, 1000 and $100 \mu \mathrm{m}$ were blended together. This means that the bacterial composition changed when the particle size of alfalfa meal decreased from 100 to $10 \mu \mathrm{m}$. Similarly, a difference was also observed in the composition of archaea between the four treatments (Fig. 2B). The 2500 and $1000 \mu \mathrm{m}$ groups were clustered thoroughly into one clade first and then mingled together, and the distance was larger than 0.2 between the two groups. The 100 and 10 $\mu \mathrm{m}$ groups mixed together and could not be distinguished, and the distance was less than 0.1. This means archaea is kept stable when the particle size of alfalfa meal larger than $1000 \mu \mathrm{m}$, and 
256 it is altered when the particle size meal is lowered less than $100 \mu \mathrm{m}$. In addition, the archaea in

257 the caecum of rabbit is changed earlier than bacteria as alfalfa meal particle size decreased.

258

259

260

261

262

263

264

265

266

267

268

269

270

271

272

273

274

275

276

277

278

279

280

A PCoA plot of overall diversity based on weighted UniFrac metric was generated (Fig. 3).

The closer the distance between points means the more similar the community structure of the two samples. The PCoA plot demonstrated that the bacterial community between $10 \mu \mathrm{m}$ group and other three treatments could be clearly distinguished $(P<0.01)$. However, the bacterial community among 2500,1000 and $100 \mu \mathrm{m}$ groups could not be obvious isolated $(P>0.05)$, and PCo1 accounted for 32.2\% (Fig. 3A; Table S2). In addition, the six archaeal samples of group 100 and $10 \mu \mathrm{m}$ were mixed together $(P=0.995)$ but could be separated thoroughly from group 2500 and $1000 \mu \mathrm{m}(P=0.025)$, and the PCo1 accounted for 98.7\% (Fig. 3B; Table S2). And the same result was obtained in our unweighted UniFrac metric analysis (Fig. S3). This again, proved that the archaeal composition structure changed before the bacterial structure, and the uniformity of archaea is better with the decrease of alfalfa meal particle size.

\section{Taxonomy of rabbit caecum microbial composition}

1

The sequences in the present experiment were finally annotated as bacteria and archaea, a total of 26 bacterial phyla and 3 archaeal phyla are identified. As for the bacteria, among which 23 phyla were detected in the 2500 and $100 \mu \mathrm{m}$ groups, and 21 and 24 phyla were obtained in 1000 and $10 \mu \mathrm{m}$ group, respectively. Figure 4 presents the relative abundance of microbial composition at the phylum level of different treatments. There were only 3 bacterial phyla with relative abundance larger than 1\% in 2500, 1000 and $100 \mu \mathrm{m}$ groups (Fig. 4A), and the two most abundant phyla were Firmicutes $(58.69 \pm 0.114 \%, 67.77 \pm 0.105 \%$ and $67.82 \pm 0.097 \%)$ and Bacteroidetes $(36.05 \pm 0.118 \%, 26.24 \pm 0.114 \%$ and $26.20 \pm 0.105 \%)$, followed by Proteobacteria $(2.69 \pm 0.003 \%, 3.37 \pm 0.005 \%$ and $3.40 \pm 0.004 \%)$. At the meanwhile, the $10 \mu \mathrm{m}$ 
281 group had 4 bacterial phyla with relative abundance above 1\%. In addition to the three 282 dominating phyla, Firmicutes $(68.50 \pm 0.052 \%)$, Bacteroidete $(23.96 \pm 0.056 \%)$ and 283 Proteobacteria $(3.34 \pm 0.002 \%)$, the relative abundance of Tenericutes $(2.08 \pm 0.012 \%)$ was also 284 greater than $1 \%$. The archaeal abundance analysis showed that the highest relative abundance was Euryarchaeota (over 99.9\%) in all of the four treatment groups (Fig. S2). The remaining archaeal abundance (Thaumarchaeota and Miscellaneous Crenarchaeotic Group) were less than 287 $0.1 \%$.

288

289

290

291

292

293

294

295

296

297

298

299

300

301

302

303

304

305

306

307

At the genus level, the bacteria kingdom is composed of 465 genera, whereas only 26 genera with relative abundance larger than $1 \%$, among which 10 of them were unclassified. The number of genera with relative abundance greater than $1 \%$ in the four treatment groups were 19 $(2500 \mu \mathrm{m}), 23(1000 \mu \mathrm{m}), 22(100 \mu \mathrm{m})$ and $20(10 \mu \mathrm{m})$, respectively. The most abundant genera (relative abundance more than 4\%) were Unclassified Bacteroidales S24-7 group (20.39 \pm 0.112\%), Ruminococcaceae UCG-014 (13.25 \pm 0.101\%), Lachnospiraceae NK4A136 group $(10.73 \pm 0.065 \%)$ and Rikenellaceae RC9 gut group $(5.00 \pm 0.066 \%)$ in the $2500 \mu \mathrm{m}$ group. Unclassified Bacteroidales S24-7 group $(14.48 \pm 0.087 \%$ and $14.56 \pm 0.088 \%)$, Ruminococcaceae UCG-014 (9.34 \pm 0.040\% and $11.55 \pm 0.097 \%)$, Lachnospiraceae NK4A136 group $(8.80 \pm 0.046 \%$ and $9.61 \pm 0.035 \%)$, unclassified Clostridiales vadinBB60 group $(5.72 \pm$ $0.060 \%$ and $4.86 \pm 0.015 \%)$ and Ruminococcaceae NK4A214 group $(4.71 \pm 0.024 \%$ and $4.39 \pm$ $0.027 \%$ ) were the most two abundant genera in 1000 and $100 \mu \mathrm{m}$ groups. In the $10 \mu \mathrm{m}$ group, Ruminococcaceae UCG-014 (33.82 \pm 9.752\%) and Unclassified Bacteroidales S24-7 (11.81 \pm $2.876 \%$ ) group were the two most abundant genera. The relative abundance of the 10 unclassified genera accounted for $29.45 \%, 20.55 \%, 30.34 \%$ and $24.86 \%$ in $2500,1000,100$ and $10 \mu \mathrm{m}$ groups, respectively (Fig. 5A).

Table 2 shows the significantly affected bacteria by the decrease of alfalfa particle size. Ruminococcaceae UCG-014 $(P<0.001)$ and Lactobacillus $(P=0.043)$ were increased while the alfalfa particle size decreased, while the relative abundance of Lachnospiraceae NK4A136 group $(P=0.016)$, Ruminococcaceae NK4A214 $(P=0.044)$, Ruminococcaceae UCG-005 $(P=0.012)$, 
308

309

310

311

312

313

314

315

316

317

318

319

320

321

322

323

324

325

326

327

328

329

330

331

332

Christensenellaceae $R-7$ group $(P=0.019)$, Lachnospiraceae other (Family) $(P=0.011)$ and Ruminococcaceae UCG-013 $(P=0.021)$ were decreased .

Meanwhile, a total of 10 genera were assigned from the sequences of archaea, however only 4 genera were classified. Archaeal classification at the genus level demonstrated that the dominating genus in caecum of rabbits was Methanobrevibacter, and its relative abundance was significantly increased from $62.48 \%$ to $90.40 \%$ as the particle size of alfalfa decreased from 2500 to $10 \mu \mathrm{m}(P<0.001)$. The Methanosphaera was the second largest genus in the caecum of rabbits, and its relative abundance decreased from $35.47 \%$ to $8.26 \%$ with the decrease of alfalfa particle size $(P<0.001)$ (Fig. 5B; Table 2).

\section{DISCUSSION}

In the present work, we attempted to study the impact of different fiber particle size on the caecal microflora of rabbits. Variations in the microbial community structure of caecum in rabbits were observed according to the decrease of particle size of alfalfa hay, and the archaea responsed earlier than bacteria when the particle size of alfalfa decreased.

Effects of fiber particle size on growth performance and digestibility of nutrients in rabbit has been assessed in previous studies (Gidenne et al., 1991; Romero et al., 2011; Liu et al., 2018), however to the best of our knowledge, this is the first implementation of high throughput sequencing technology to investigate the relationship between fiber particle size and caecal microflora of rabbits. We found that the alpha diversity index of the finest particle size was the highest numerically, although there was no significant difference in bacterial diversity in this study. We have previously confirmed that the growth performance of rabbits at group $10 \mu \mathrm{m}$ particle size is the best (Liu et al., 2018). There are also studies showing that high diversity of microorganisms is beneficial to animals (Arrazuria et al., 2016). However, we observed the 
333 Shannon index of archaea decreased significantly with the decrease of particle size, which was

334

335

336

337

338

339

340

341

342

343

344

345

346

347

348

349

350

351

352

353

354

355

356

357

358

359

contrary to the change of ADG (average daily gain) and ADFI (average daily feed intake) in rabbits. This may be due to the low content of archaea $(0.2 \pm 0.23 \%)$ in the cecum ( Liu et al., 2016) and its change in diversity was insufficient to affect the growth performance of rabbits.

We also discovered that microbial abundance varied with the different particle size of alfalfa, this is consistent with previous studies on poultry (Engberg et al., 2004; Santos et al., 2006). Furthermore, bacteria belonging to the phylum Firmicutes dominated the bacterial community of rabbit caecum in all of the 4 treatments $(58.69 \% \sim 68.50 \%)$, and these results are supported by a number of existing studies (Bänerl et al., 2014; Combes et al., 2011; Zhu et al., 2015). Monteils et al. (2008) reported that the Firmicutes in the rabbit caecum contain a large number of fiber-decomposing bacteria, this coincides with the fact that rabbits are adapted to high-fiber diets. Same as previous research (Zhu et al., 2015), the abundance of Bacteroidetes $(23.96 \% \sim 36.05 \%)$ is the second largest bacterial community in our study, it is indicated that Bacteroidetes do play an important role in intestinal digestion in rabbits. Research has suggested that there were high abundance of Bacteroidetes in the intestine of herbivore animals related to the higher fiber content of food intake (Crowley et al., 2017). Contrarily, we found that the relative abundance of Firmicutes and Bacteroidetes were slightly different from previous studies (Arrazuria et al., 2016; Jin et al., 2018). One of reason maybe that the result of sex selection in rabbits (Arrazuria et al., 2016). Moreover, it may also be the fact that the individual cages was not used in this work as previous reports (Jin et al., 2018). Certainly, it was possibly caused by feeding coccidiostatic as well. But the specific reasons for the differences still need to be proved by further experiments.

Proteobacteria are commonly found in the gastrointestinal tract of animals and exist as the dominant bacteria of some animals (Jami et al., 2013; Fang et al., 2012). In present study, Proteobacteria $(2.69 \% \sim 3.37 \%)$ was the dominating bacteria in rabbit caecum after Firmicutes and Bacteroidetes. At the same time, we observed that the relative abundance of Proteobacteria was significantly increased with the decrease of alfalfa particle size. This may be due to the

Peer) reviewing PDF | (2019:02:35028:3:0:NEW 1 Sep 2019) 
360

361

362

363

364

365

366

367

368

369

370

371

372

373

374

375

376

377

378

379

380

381

382

383

384

385

386 Lactobacillus as a beneficial microorganism can inhibit the growth of pathogenic bacteria,

relative increase of crude protein content or more protein binding site in the diet when the particle size of alfalfa decreased (Table S1). This was in line with the opinion that Proteobacteria was related to protein digestion (Jami et al., 2013; Liu et al., 2016). As the main genus of Proteobacteria, the relative abundance of Succinivibrionaceae UCG-002 was significant increased with the reduction of particle size of alfalfa. Therefore, we assumed that Succinivibrionaceae UCG-002 might be a microorganism involved in protein digestion. But further work is needed to confirm this speculation. In addition, it was more interesting that the relative abundance of Tenericutes $(2.11 \%)$ in the $10 \mu \mathrm{m}$ group was significantly higher than the other three groups and became one of the major microbe of the caecum. Nevertheless, Arrazuria et al. (2016) found that the relative abundance of Tenericutes only was $0.43 \%$ in the caecum of regular diet fed rabbits, which was similar to the Tenericutes abundance of the other three treatments in this study. Therefore, it is regarded that the increased relative abundance of Tenericutes was attributed by the ultrafine smashing of alfalfa. It is a pity that the specific role of Tenericutes in the cecum of rabbits remains unrevealed.

In terms of genera, Unclassified Bacteroidales S24-7 and Ruminococcaceae UCG-014 were the two most abundant bacteria in rabbit caecum. However, Bäuerl et al. (2014) reported that the most frequent genera in healthy rabbits were Ruminococcus and Alistipes. This might resulted from the different rabbit species and diets used in two studies. It was reported that the specific role of Unclassified Bacteroidales S24-7 in the intestine was to breakdown starch, complex polysaccharides and fiber (Lan et al., 2006). Studies have shown that excessive oxalate can cause kidney stones by complexing calcium (Whiteside et al., 2015), while Unclassified Bacteroidales S24-7 can degrade oxalate (Ormerod et al., 2016). This further confirmed the important role of Bacteroidetes in the cecum of rabbits. Furthermore, previous studies have shown that family Ruminococcaceae was closely related to fiber degradation (Wood, 1988; Ezaki, 2015). And that the Ruminococcaceae UCG-014 as the main genus of Ruminococcaceae, should also play a role in fiber degradation. This is consistent with the common sense of rabbits as a herbivore. 
387 improve the structure of intestinal flora, strengthen the intestinal barrier function, thereby 388 enhancing the immunity of host (Wang et al., 2015). It was well documented that feed particle 389 size has various effects on the growth of beneficial bacteria such as intestinal Lactobacillus. Bao 390 et al. (2016) found that the number of Lactobacillus in the intestine of pigs increased first and 391 then decreased as the size of corn crushed increased. Singh et al. (2014) evidenced that caecal 392 Lactobacillus increased linearly with the increase of corn grinding size. Contrarily, our study 393 found that the abundance of Lactobacillus increased with the decrease in particle size of alfalfa hay. This may be due to the slowdown of chyme passage when the particle size of fibers decreased, thereby enhancing the adhesion of Lactobacillus (Pickard and Stevens, 1972). Our 396 previous study (Liu et al., 2018) also found that the ADG and ADFI of rabbits increased significantly, while the FCR decreased with the decrease of alfalfa particle size. This indicates that Lactobacillus maybe have a positive effect on the growth performance of rabbits, this was also been confirmed by Wang et al. (2017). In addition, only Ruminococcaceae UCG-014 and Lactobacillus (Firmicutes) had the same changes trend among the core genera. Furthermore, with the exception that Ruminococcaceae UCG-005 was increased first and then decreased as the particle size of alfalfa decreased, the abundance of other genera (abundance $>1 \%$ ) of Firmicutes (mainly Lachnospiraceae NK4A136 group and Ruminococcaceae NK4A214 group) were significantly lowered when particle size decreased. This led to no statistical difference in the abundance of Firmicutes among treatments. stage of microbial organic matter decay in the digestive system (Cavicchioli, 2011). Thus, the methanogenic archaea are widely found in the gastrointestinal tract of herbivores and many methanogens have been isolated and identified from different animals (Jin et al., 2017; Wright et al., 2004). However, almost all of the archaea found in the gastrointestinal tract of animals originated from Euryarchaeota (Jin et al., 2017; Zhu et al., 2016). This was consistent with our 412 study. The results of our work showed that the Euryarchaeota almost covered the whole archaeal 413 phyla in all treatment groups (over 99.9\%). Therefore, we believe that the Euryarchaeota plays a 
414 major role in the rabbit caecum.

415 It is reported that the archaeal community in rabbit caecum is unique and of low complexity 416 with few dominating species, Methanobrevibacter and Methanosphaera genus usually were the 417 two most abundantly distributed genera (Zhu et al., 2016; Kušar and Avguštin, 2010). In 418 particular, the genus Methanobrevibacter was considered to be the absolute dominanting core 419 genus (Wright et al., 2004; Zhu et al., 2016), which is in agreement with the findings of current study. Researches proved that Methanobrevibacter and Methanosphaera were two dominanting $\mathrm{H}_{2}$-consuming organisms that were often found distributed in the hindgut of humans or animals, catalyzing the conversion of hydrogen and carbon dioxide, methanol, etc into methane (Kušar and Avguštin, 2010). Here, we discovered that fed alfalfa with different particle sizes could adjust the abundance and diversity of methanogens. As the alfalfa particle size decreased, the relative abundance of Methanobrevibacter increased at the cost of a reduction in Methanosphaera. This was confirmed by our team, that when the relative abundance of Methanobrevibacter increased the methane production increased (Liu et al., 2018). This phenomenon could be explained by the two aspects. At one hand, some earlier studies found that the particle size of fibrous ingredients was known to affect retention time of digesta in the intestine (Gidenne et al., 1991; Gidenne et al., 1993). The smaller the fiber particle size, the longer retention time of the feed in the intestine. This prolongs the fermentation time of the feed in the caecum, resulting in a larger amount methane production. On the other hand, compared to Methanobrevibacter, the production of methane by Methanosphaera has certain limitations. Methanosphaera can not produce methane from hydrogen and carbon dioxide, formate, acetate, but can only use methanol and hydrogen to produce methane, which requires the participation of ATP (Fricke et al., 2006; Miller and Wolin, 1985). Methanosphaera and Methanobrevibacter consume 1.3 moles of methanol and 1 mole of carbon dioxide, respectively, to produce 1 mole of 438 methane (Fricke et al., 2006; Hook et al., 2010). This means that the capacity of 439 Methanobrevibacter to produce methane is larger than that of Methanosphaera. Consequently, 440 exchange abundance of Methanosphaera and Methanobrevibacter increased methane production. 


\section{NUCLEOTIDE SEQUENCE ACCESSION NUMBERS.}

Sequences of this project have been deposited into the Sequence Read Archive (SRA) of the NCBI nucleotide database under accession number PRJNA542420.

\section{CONCLUSION} are produced earlier in time. The bacterial populations changed when the alfalfa fiber particle size decrease from 100 to $10 \mu \mathrm{m}$, whereas the archaeal populations changed while the fiber particle size decrease from 1000 to $100 \mu \mathrm{m}$. In terms of bacteria, Ruminococcaceae UCG-014 and Lactotobacillus increased whereas the Lachnospiraceae NK4A136 group, Ruminococcaceae NK4A214 group decreased when the fiber particle size decreased from 2500 to $10 \mu \mathrm{m}$. As for the archaeal populations, the Methanobrevibacter increased at the cost of redution of Methanosphaera. The gastrointestinal microbial populations could be manipulated by feeds processing technology in the aim of promoting animal production performance.

REFERENCE

Voris L, Marcy LF, Thacker EJ, Wainio WW. 1940. Digestible nutrients of feeding stuffs for the domestic rabbit. Journal of Agricultural Research 61: 673-683. 
464

465

466

467

468

469

470

471

472

473

474

475

476

477

Slade LM, Hintz HF. 1969. Comparison of digestion in horses, ponies, rabbits and guinea pigs. Journal of Animal Science 28: 842-843. DOI 10.2527/jas1969.286842x.

Chiou PW, Yu B, Lin C. 1994. Effect of different components of dietary fiber on the intestinal morphology of domestic rabbits. Comparative Biochemistry and Physiology Comparative Physiology 108: 629-438. DOI 10.1016/0300-9629(94)90349-2.

Cheeke PR. 1987. Rabbit feeding and nutrition. Rabbit Feeding and Nutrition 81: xiii-xiv.

Jenkins JR. 1999. Feeding recommendations for the house rabbit. Veterinary Clinics of North America: Exotic Animal Practice 2: 143-151. DOI 10.1016/S1094-9194(17)30144-5.

García J, Deblas JC, Carabaño R, Garcia P. 1995. Effect of type of lucerne hay on caecal fermentation and nitrogen contribution through caecotrophy in rabbits. Reproduction Nutrition Development 35: 267-275. DOI 10.1016/0926-5287(96)80196-1.

García J, Pérez-Alba L, Alvarez C, Rocha R, Ramos M, Deblas C. 1995. Prediction of the nutritive value of lucerne hay in diets for growing rabbits. Animal Feed Science and Technology 54: 33-44. DOI 10.1016/0377-8401(94)00759-3.

Nicholson JK, Holmes E, Kinross J, Burcelin R, Gibson G, Jia W, Pettersson S. 2012. Host-gut microbiota metabolic interactions. Science 336: 1262-1267. DOI 10.1126/science.1223813.

Jami E, Israel A, Kotser A, Mizrahi I. 2013. Exploring the bovine rumen bacterial community from birth to adulthood. The ISME Journal 7: 1069-1079. DOI 10.1038/ismej.2013.2.

García J, Carabaño R, Pérezalba L, Deblas C. 2000. Effect of fiber source on cecal fermentation and nitrogen recycled through cecotrophy in rabbits. Journal of Animal Science 78: 638-646. DOI 10.1046/j.1439-0396.2000.00257.x.

Chang Y, Qin YH, Xiong YQ, Du YC, Meng QX. 2006. Response of growth performance, cecal fermentation traits and in vitro gas production to substitution of soyhulls for lignified fiber in rabbit diets. Asian Australasian Journal of Animal Sciences 20: 45-51. DOI 10.5713/ajas.2007.45. 
488

489

490

491

492

493

494

495

496

497

498

499

500

501

502

503

504

505

506

507

508

509

510

511

Cao Z, Liang JB, Liao XD, Wright AD, Wu YB, Yu B. 2016. Effect of dietary fiber on the methanogen community in the hindgut of Lantang gilts. Animal 10: 1666-1676. DOI 10.1017/S1751731116000525.

Boulahrouf A, Fonty G, Gouet P. 1991. Establishment, counts, and identification of the fibrolytic microflora in the digestive tract of rabbit. Influence of feed cellulose content. Current Microbiology 22: 21-25. DOI 10.1007/BF02106208.

Bennegadi N, Fonty G, Millet L, Gidenne T, Licois D. 2003. Effects of age and dietary fibre level on caecal microbial communities of conventional and specific pathogen-free rabbits. Microbial Ecology in Health and Disease 15: 23-32. DOI 10.1080/08910600310015574.

Gidenne T, Carré B, Segura M, Lapanouse A, Gomez J. 1991. Fibre digestion and rate of passage in the rabbit: effect of particle size and level of lucerne meal. Animal Feed Science and Technology 32: 215-221. DOI 10.1016/0377-8401(91)90025-N.

Gidenne T. 1993. Measurement of the rate of passage in restrictedfed rabbits: effect of dietary cell wall level on the transit of fibre particles of different sizes. Animal Feed Science and Technology 42: 151-163. DOI 10.1016/0377-8401(93)90030-N.

Nicodemus N, Redondo R, Pérez-Alba L, Carabañoa R, Deblasa JC, Garcíaa J. 2010. Effect of level of fibre and type of grinding on the performance of rabbit does and their litters during the first three lactations. Livestock Science 129: 186-193. DOI 10.1016/j.livsci.2010.01.023.

Romero C, Nicodemus N, Martínez de Morentin CG, García AI, Deblas C. 2011. Effect of grinding size of barley and dehydrated alfalfa on performance and body composition of does during their early reproductive cycles. Livestock Science 140: 55-61. DOI 10.1016/j.livsci.2011.02.010.

Caporaso JG, Lauber CL, Walters WA, Berg-Lyons D, Lozupone CA, Turnbaugh PJ, Fierer N, Knight R. 2011. Global patterns of $16 \mathrm{~S}$ rRNA diversity at a depth of millions of sequences per sample. Proceedings of the National Academy of Sciences 108: 4516-4522. DOI 10.1073/pnas.1000080107.

Peer] reviewing PDF | (2019:02:35028:3:0:NEW 1 Sep 2019) 
512

513

composition of known and uncultured archaeal lineages in anaerobic or anoxic wastewater treatment sludge. Microbial Ecology 69: 586-596. DOI 10.1007/s00248-014-0525-z.

Williams R, Peisajovich SG, Miller OJ, Magdassi S, Tawfik DS, Griffiths AD. 2006. Amplification of complex gene libraries by emulsion PCR. Nature Methods 3: 545-550. DOI 10.1038/nmeth896.

Rashmi KS. 2016. Emulsion PCR: Techniques and Applications. Methods in Molecular Biology 1392: 33-42. DOI 10.1007/978-1-4939-3360-0_4.

Qiu X, Wu L, Huang H, McDonel PE, Palumbo AV, Tiedje JM, Zhou J. 2001. Evaluation of PCRGenerated Chimeras, Mutations, and Heteroduplexes with 16S rRNA Gene-Based Cloning. Applied and Environmental Microbiology 67: 880-887. DOI 10.1128/AEM.67.2.880-887.2001.

Caporaso JG, Lauber CL, Walters WA, Berg-Lyons D, Huntley J, Fierer N, Owens SM, Betley J, Fraser L, Bauer M, Gormley N, Gilbert JA, Smith G, Knight R. 2012. Ultra-high-throughput microbial commutunity analysis on the illumina HiSeq and MiSeq platforms. ISME Journal: Multidisciplinary Journal of Microbial Ecology 6: 1621-1624. DOI 10.1038/ismej.2012.8.

Caporaso JG, Kuczynski J, Stombaugh J, Bittinger K, Bushman FD, Costello EK, Fierer N, Peña AG, Goodrich JK, Gordon JI, Huttley GA, Kelley ST, Knights D, Koenig JE, Ley RE, Lozupone CA, McDonald D, Muegge BD, Pirrung M, Reeder J, Sevinsky JR, Turnbaugh PJ, Walters WA, Widmann J, Yatsunenko T, Zaneveld J, Knight R. 2010. QIIME allows analysis of high-throughput community sequencing data. Nature Methods 7: 335-336. DOI 10.1038/nmeth.f.303.

Magoč T, Salzberg SL. 2011. FLASH: fast length adjustment of short reads to improve genome assemblies. Bioinformatics 27: 2957-2963. DOI 10.1093/bioinformatics/btr507.

Bolger AM, Lohse M, Usadel B. 2014. Trimmomatic: a flexible trimmer for Illumina sequence data. Bioinformatics 30: 2114-2120. DOI 10.1093/bioinformatics/btu170.

Edgar RC. 2013. UPARSE: Highly accurate OTU sequences from microbial amplicon reads. Nature Methods 10: 996 . DOI 10.1038/nmeth.2604. 
536

537

538

539

540

541

542

543

544

545

546

547

548

549

550

551

552

553

554

555

556

557

Edgar RC, Haas BJ, Clemente JC, Quince C, Knight R. 2011. UCHIME improves sensitivity and speed of chimera detection. Bioinformatics 27: 2194. DOI 10.1093/bioinformatics/btr381.

Quast C, Pruesse E, Yilmaz P, Gerken J, Schweer T, Yarza P, Peplies J, Glöckner FO. 2013. The SILVA ribosomal RNA gene database project: improved data processing and web-based tools. Nucleic Acids Research 41: D590-D596. DOI 10.1093/nar/gks1219.

Caporaso JG, Bittinger K, Bushman FD, DeSantis TZ, Andersen GL, Knight R. 2010. PyNAST: a flexible tool for aligning sequences to a template alignment. Bioinformatics 26: 266-267. DOI 10.1093/bioinformatics/btp636.

Price MN, Dehal PS, Arkin AP. 2010. Fasttree 2 - approximately maximum-likelihood trees for large alignments. PLOS ONE 5(3): e9490. DOI 10.1371/journal.pone.0009490.

Kembel SW, Cowan PD, Helmus MR, Cornwell WK, Morlon H, Ackerly DD, Blomberg SP, Webb CO. 2010. Picante: $R$ tools for integrating phylogenies and ecology. Bioinformatics 26(11): 1463-1464. DOI 10.1093/bioinformatics/btq166.

Chen J, Bittinger K, Charlson ES, Hoffmann C, Lewis J, Wu GD, Collman RG, Bushman FD, Li H. 2012. Associating microbiome composition with environmental covariates using generalized UniFrac distances. Bioinformatics 28(16): 2106-2113. DOI 10.1093/bioinformatics/bts342.

Liu SQ, Yuan M, Jin DX, Wang ZS, Zou HW, Wang LZ, Xue B, Wu D, Tian G, Cai JY, Yan TH, Peng QH. 2018. Effects of the particle of ground alfalfa hay on the growth performance, methane production and archaeal populations of rabbits. PLOS ONE 13(9): e0203393. DOI 10.1371/journal.pone.0203393.

Engberg RM, Hedemann MS, Steenfeldt S, Jensen BB. 2004. Influence of whole wheat and xylanase on broiler performance and microbial composition and activity in the digestive tract. Poultry Science 83: 925-938. DOI 10.1093/ps/83.6.925.

Santos FBO, Santos Jr AA, Ferket PR,Sheldon BW. 2006. Influence of grain particle size and insoluble fiber content on salmonella colonization and shedding of turkeys fed corn-soybean meal diets. 
Bäuerl C, Collado MC, Zúñiga M, Blas E, Pérez Martínez G. 2014. Changes in cecal microbiota and mucosal gene expression revealed new aspects of epizootic rabbit enteropathy. PLOS ONE 9(8): e105707. DOI 10.1371/journal.pone.0105707.

Combes S, Michelland RJ, Monteils V, Cauquil L, Soulié V, Tran NU, Gidenne T, Fortun-Lamothe L. 2011. Postnatal development of the rabbit caecal microbiota composition and activity. FEMS microbiology ecology 77: 680-689. DOI 10.1111/j.1574-6941.2011.01148.x.

Zhu Y, Wang C, Li F. 2015. Impact of dietary fiber/starch ratio in shaping caecal microbiota in rabbits. Canadian Journal of Microbiology 61: 771-84. DOI 10.1139/cjm-2015-0201.

Monteils V, Cauquil L, Combes S, Godon JJ, Gidenne T. 2008. Potential core species and satellite species in the bacterial community within the rabbit caecum. Fems Microbiology Ecology 66: 620-629. DOI 10.1111/j.1574-6941.2008.00611.x.

Crowley EJ, King JM, Wilkinson T, Worgan HJ, Huson KM, Rose MT, McEwan NR. 2017. Comparison of the microbial population in rabbits and guinea pigs by next generation sequencing. PLOS ONE 12(2): e0165779. DOI 10.1371/journal.pone.0165779.

Jin DX, Zou HW, Liu SQ, Wang LZ, Xue B, Wu D, Tian G, Cai JY, Yan TH, Wang ZS \& Peng QH. 2018. The underlying microbial mechanism of epizootic rabbit enteropathy triggered by a low fiber diet. Scientific Reports 8(1): 12489. DOI 10.1038/s41598-018-30178-2.

Fang W, Fang Z, Zhou P, Chang F, Hong Y, Zhang X, Peng H, Xiao Y. 2012. Evidence for lignin oxidation by the giant panda fecal microbiome. PLoS ONE 7(11): e50312. DOI 10.1371/journal.pone.0050312.

Liu K, Xu Q, Wang L, Wang J, Guo W, Zhou M. 2016. The impact of diet on the composition and relative abundance of rumen microbes in goat. Asian Australasian Journal of Animal Sciences 30: 531-537. DOI 10.5713/ajas.16.0353. 
584

585

586

587

588

589

590

591

592

593

594

595

596

597

598

599

600

601

602

603

604

605

606

607

Arrazuria R, Elguezabal N, Juste RA, Derakhshani H, Khafipour E. 2016. Mycobacterium avium subspecie sparatuberculosis infection modifies gut microbiota under different dietary conditions in a rabbit model. Frontiers in Microbiology 7: 446. DOI 10.3389/fmicb.2016.00446.

Whiteside SA, Razvi H, Dave S, Reid G, Burton JP. 2015. The microbiome of the urinary tract-a role beyond infection. Nature Reviews Urology 12: 81-90. DOI 10.1016/j.juro.2015.09.053.

Ormerod KL, Wood DLA, Lachner N, Gellatly SL, Daly JN, Parsons JD, Dal'Molin CGO, Palfreyman RW, Nielsen LK, Cooper MA, Morrison M, Hansbro PM, Hugenholtz P. 2016. Genomic characterization of the unculturedBacteroidalesfamilyS24-7inhabiting the guts of homeothermic animals. Microbiome 4(1): 36. DOI 10.1186/s40168-016-0181-2.

Lan PT, Sakamoto M, Sakata S, Benno Y. 2006. Bacteroides barnesiae sp nov. Bacteroides salanitronis sp nov and Bacteroides gallinarum sp nov. isolated from chicken caecum. Int J Syst Evol Microbiol 56: 2853-2859. DOI 10.1099/ijs.0.64517-0.

Wood TM. 1988. Cellulase of Ruminococcus albus. Meth. Enzyol 160: 216-221. DOI 10.1016/00766879(88)60123-6.

Ezaki T. 2015. Ruminococcus. New York: John Wiley and Sons, Ltd. DOI 10.1002/9781118960608.gbm00678.

Wang J, Tang H, Zhang C, Zhao Y, Derrien M, Rocher E, van-Hylckama Vlieg JE, Strissel K, Zhao L, Obin M, Shen J. 2015. Modulation of gut microbiota during probiotic-mediated attenuation of metabolic syndrome in high fat diet-fed mice. The ISME Journal 9: 1-15. DOI 10.1038/ismej.2014.99.

Bao Z, Li Y, Zhang J, Li L, Zhang P, Huang FR. 2016. Effect of particle size of wheat on nutrient digestibility, growth performance, and gut microbiota in growing pigs. Livestock Science 183: 33-39. DOI 10.1016/j.livsci.2015.11.013.

Singh Y, Ravindran V, Wester TJ, Molan AL, Ravindran G. 2014. Influence of feeding coarse corn on performance, nutrient utilization, digestive tract measurements, carcass characteristics, and cecal 
608

609

610

611

612

613

614

615

microflora counts of broilers. Poultry Science 93: 607-16. DOI 10.3382/ps.2013-03542.

Pickard DW, and Stevens CE. 1972. Digesta flow through the rabbit large intestine. American Journal of Physiology, 222: 1161-1166. DOI 10.1152/ajplegacy.1972.222.5.1161.

Wang C, Zhu Y, Li F, Huang L. 2017. The Effect of Lactobacillus isolates on growth performance, immune response, intestinal bacterial community composition of growing Rex Rabbits. Journal of Animal Physiology and Animal Nutrition 101: e1-e13. DOI 10.1111/jpn.12629.

Cavicchioli R. 2011. Archaea--timeline of the third domain. Nature Reviews Microbiology 9: 51-61. DOI 10.1038/nrmicro2482.

Jin D, Kang K, Wang H, Wang Z, Xue B, Wang L, Xu F, Peng Q. 2017. Effects of dietary supplementation of active dried yeast on fecal methanogenic archaea diversity in dairy cows. Anaerobe 44: 78-86. DOI 10.1016/j.anaerobe.2017.02.007.

Wright AD, Williams AJ, Winder B, Christophersen CT, Rodgers SL, Smith KD. 2004. Molecular diversity of rumen methanogens from sheep in western australia. Applied and Environmental Microbiology 70: 1263-1270. DOI 10.1128/AEM.70.3.1263-1270.2004.

Zhu Y, Sun Y, Wang C, Li F. 2016. Impact of dietary fibre:starch ratio in shaping caecal archaea revealed in rabbits. Journal of Animal Physiology and Animal Nutrition 101: 635-640. DOI 10.1111/jpn.12585.

Kušar D, Avguštin G. 2010. Molecular profiling and identification of methanogenic archaeal species from rabbit caecum. Fems Microbiology Ecology 74: 623-30. DOI 10.1111/j.1574-6941.2010.00980.x.

Fricke WF, Seedorf H, Henne A, Krüer M, Liesegang H, Hedderich R, Gottschalk G, Thauer RK. 2006. The genome sequence of methanosphaera stadtmanae reveals why this human intestinal archaeon is restricted to methanol and h2 for methane formation and atp synthesis. Journal of Bacteriology 188: 642658. DOI 10.1128/JB.188.2.642-658.2006.

Miller TL and Wolin MJ. 1985. Methanosphaera stadtmaniae, gen. nov. sp. nov.: a species that forms methane by reducing methanol with hydrogen. Archives of Microbiology 141: 116-122. 
632 Hook SE, Wright A-DG, McBride BW. 2010. Methanogens: Methane producers of the rumen and mitigation strategies. Archaea 2010: 1-11. DOI 10.1155/2010/945785. 


\section{Figure 1}

Venn diagram representation of the shared and exclusive bacterial (A) and archaeal (B) OTUs at $97 \%$ similarity level of the four treatment groups. The percentage data in parentheses is the sequence abundance of the corresponding OTUs out of the total OTU.

A

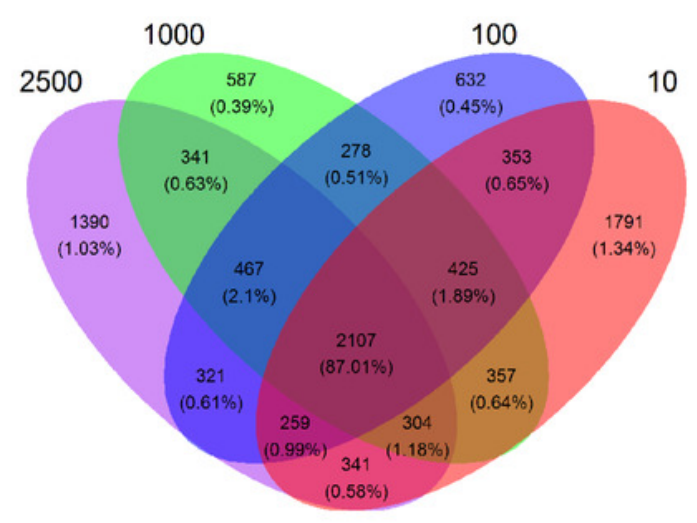

B

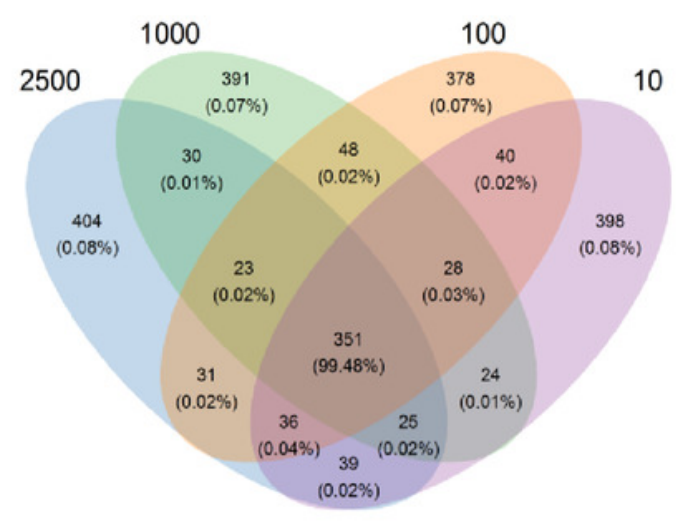


Figure 2

Hierarchical clustering of bacterial (A) and archaeal (B) communities assessed using weighted UniFrac metric analysis of OTUs at $97 \%$ similarity. The scale bar shows approximate weighted UniFrac metric similarity coefficient of 0.25 in bacteria, the archae

group $2500 \mu \mathrm{m}=$ tag number 2500-1, 2500-2, 2500-3, 2500-4, 2500-4, 2500-5 and 2500-6; group $1000 \mu \mathrm{m}=$ tag number 1000-1, 1000-2, 1000-3, 1000-4, 1000-5 and 1000-6; group $100 \mu \mathrm{m}=$ tag number 100-1, 100-2, 100-3, 100-4, 100-5 and 100-6; group $10 \mu \mathrm{m}=\mathrm{tag}$ number 10-1, 10-2, 10-3, 10-4, 10-5 and 10-6.

A

0.50 Distance (Weighted Unifrac) 0.00

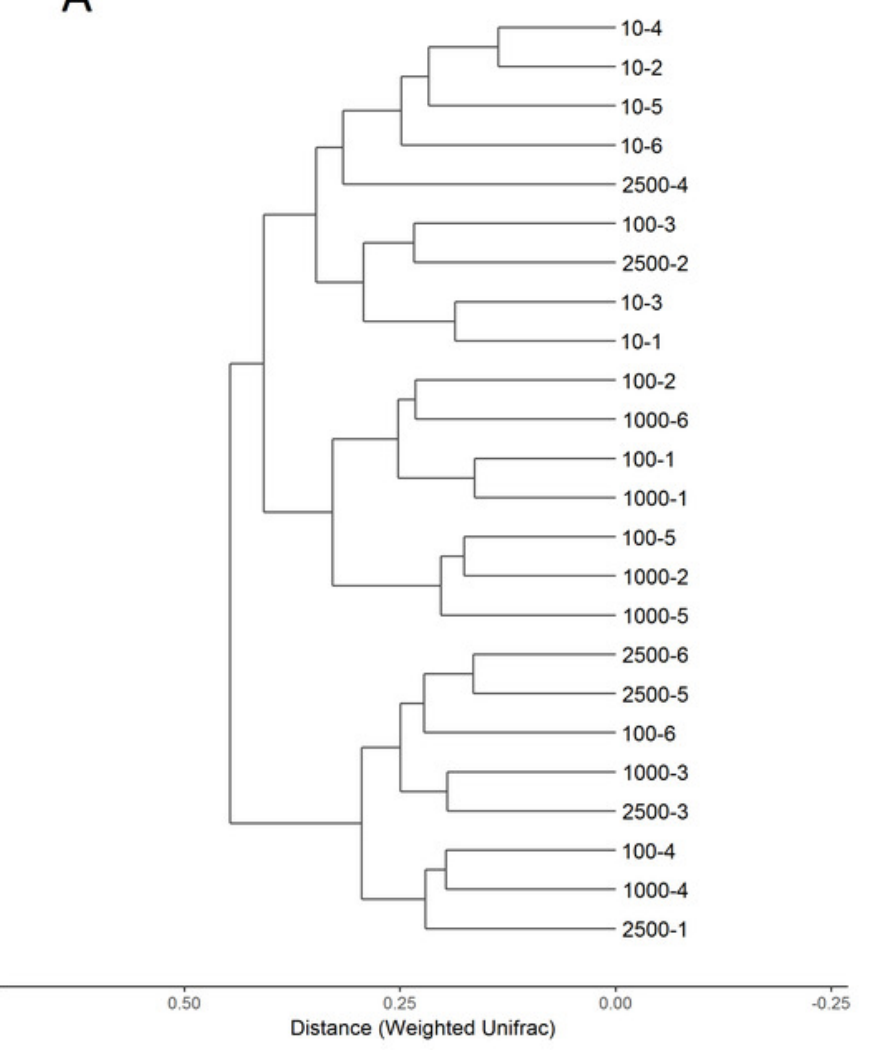
$-0.25$

B
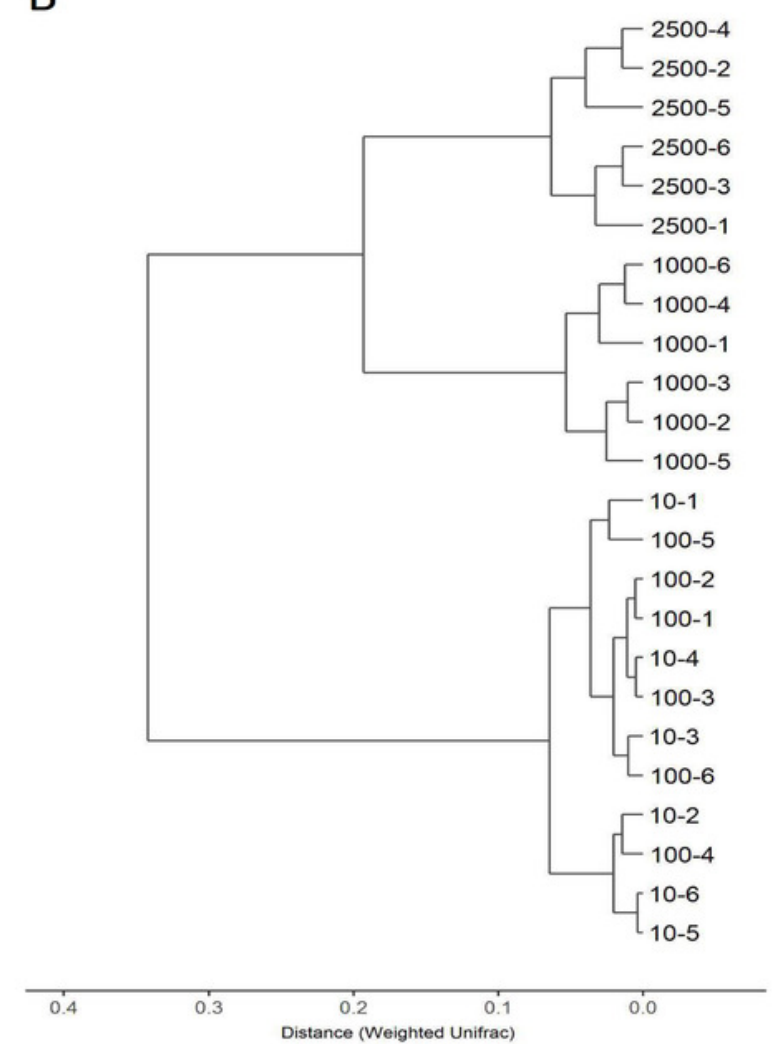
Figure 3

Principal co-ordinate analysis ( $\mathrm{PCOA}$ ) scores plot generated from rabbits caecum sample by a weighted UniFrac analysis at the $97 \%$ similarity level. A and B represent bacteria and archaea, respectively.
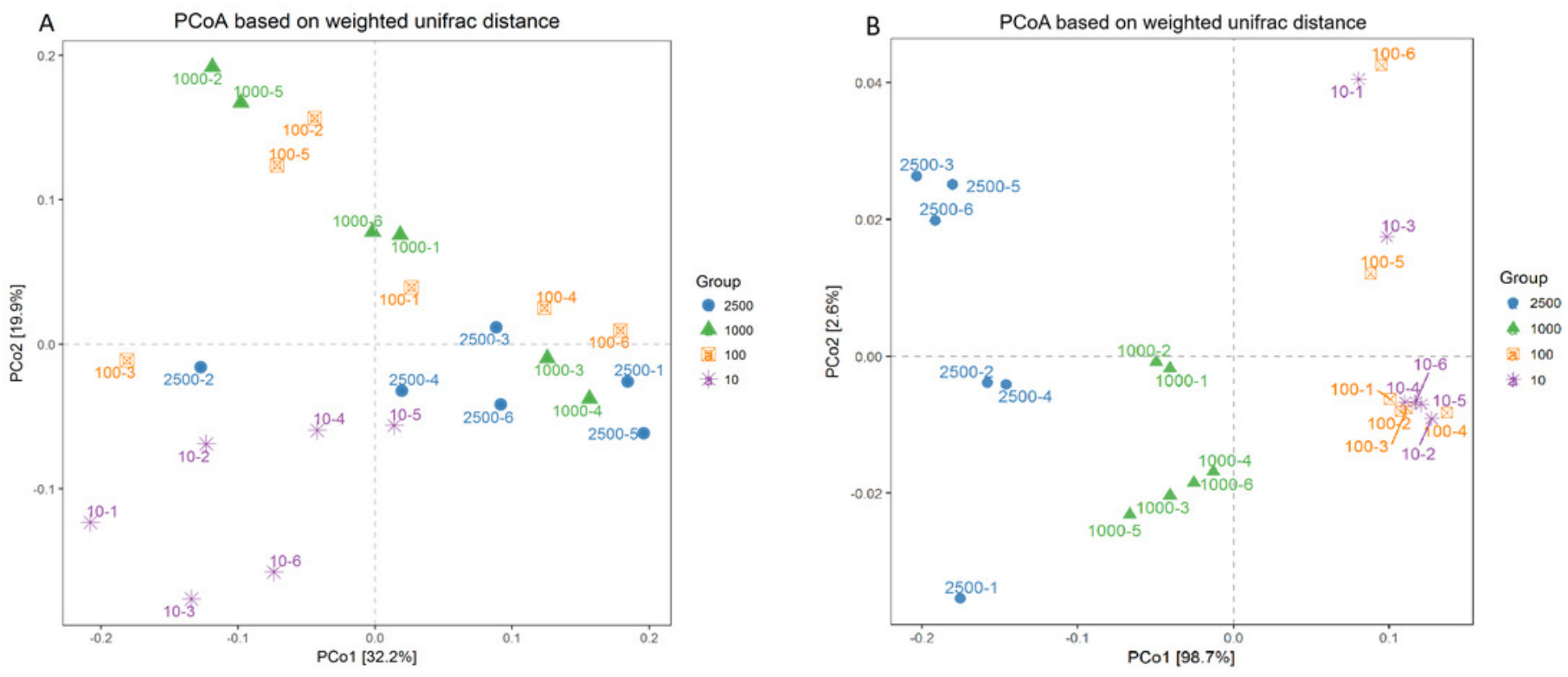


\section{Figure 4}

Phylum level composition of bacteria. A color-coded bar plot shows the average relative abundance of bacterial phyla $(>0.1 \%$ ) distribution in different treatment groups.

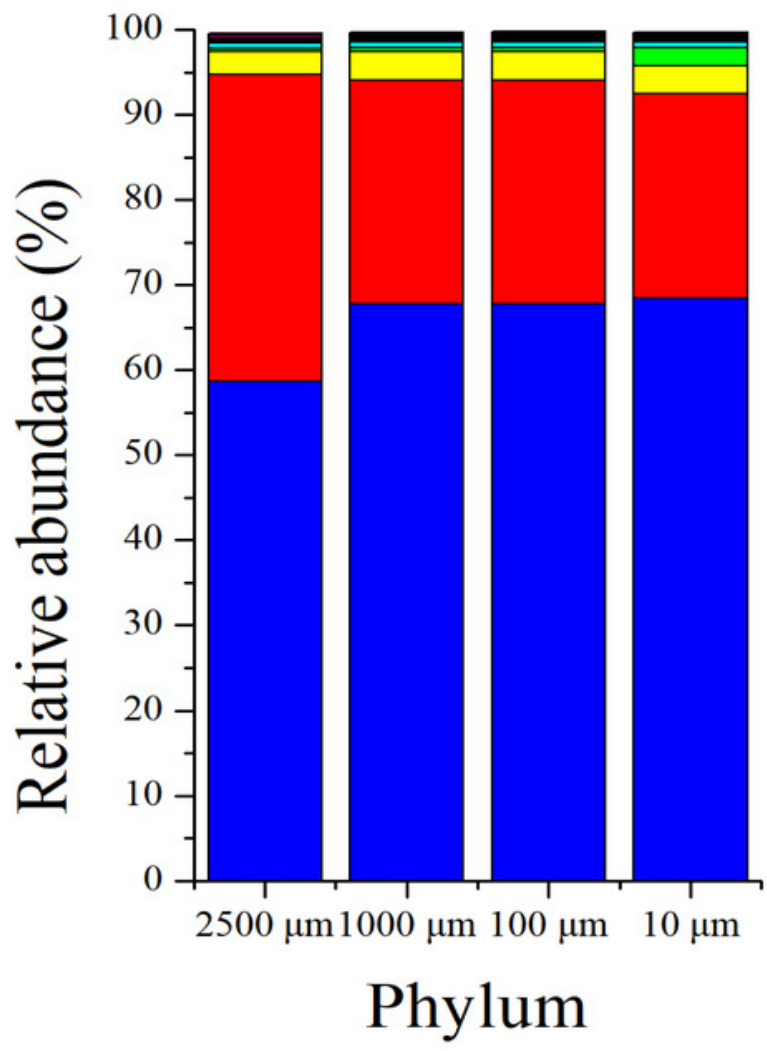

\begin{tabular}{|c|c|}
\hline & Cyanobacteria \\
\hline & | Planctomycetes \\
\hline & Verrucomicrobia \\
\hline & Actinobacteria \\
\hline & Spirochaetae \\
\hline & Saccharibacteria \\
\hline & Lentisphaerae \\
\hline & Tenericutes \\
\hline & Proteobacteria \\
\hline & Bacteroidetes \\
\hline & Firmicutes \\
\hline
\end{tabular}


Figure 5

Genus level composition. Bar plots showing average relative abundance (\%) of bacterial $(A)$ and archaeal $(B)$ in diffrent particle size. And only shows bacterial genera with relative abundance more than $1 \%$.

A

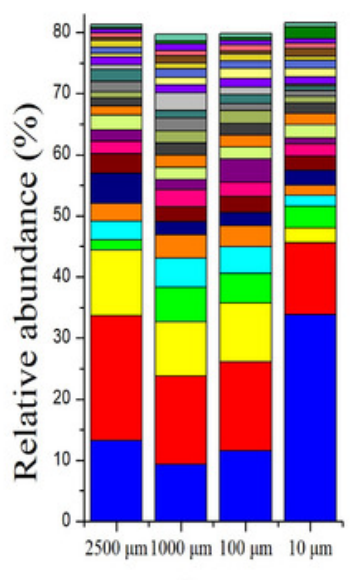

Genus

\section{B}

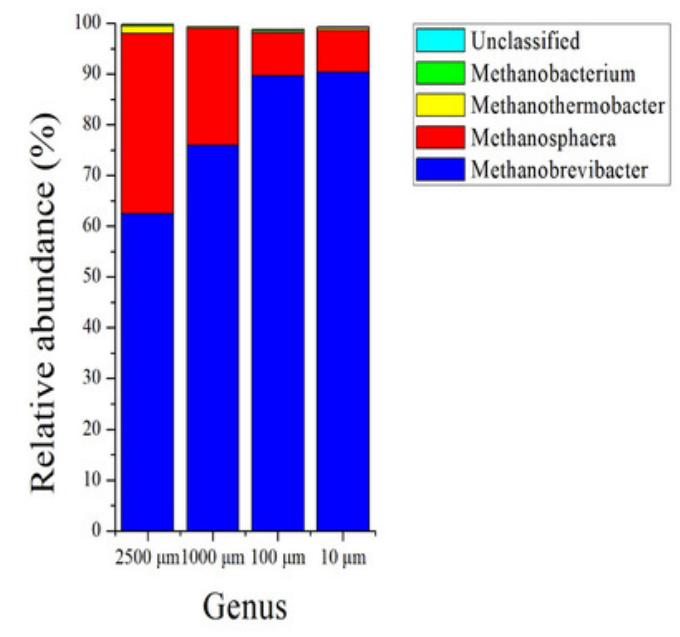




\section{Table $\mathbf{1}$ (on next page)}

The average value of alpha diversity index of caecum microbes of rabbits fed diets with different particle size of alfalfa meal 
1

Table 1

2 The average value of alpha diversity index of caecum microbes of rabbits fed diets with different particle size

3 of alfalfa meal

\begin{tabular}{lcccccc}
\hline \multirow{2}{*}{ Item $^{1}$} & \multicolumn{5}{c}{ Treatments $^{2}$} \\
\cline { 2 - 5 } & $2500 \mu \mathrm{m}$ & $1000 \mu \mathrm{m}$ & $100 \mu \mathrm{m}$ & $10 \mu \mathrm{m}$ & \\
\cline { 2 - 5 } Bacteria & & & & & \\
OTUs & 1961.33 & 1784.33 & 1815.67 & 2022.83 & 51.313 & 0.305 \\
Chao1 value & 3331.69 & 2952.54 & 2878.53 & 3373.24 & 142.157 & 0.519 \\
Shannon value & 6.07 & 6.03 & 6.12 & 6.35 & 0.054 & 0.160 \\
PD value & 164.72 & 151.87 & 154.46 & 168.19 & 3.469 & 0.228 \\
Archaea & & & & & \\
OTUs & 363.17 & 340.17 & 363.50 & 357.00 & 4.382 & 0.198 \\
Chaol value & 728.05 & 716.41 & 721.69 & 728.00 & 8.213 & 0.957 \\
Shannon value & $2.27^{\mathrm{a}}$ & $2.16^{\mathrm{b}}$ & $2.14^{\mathrm{b}}$ & $2.17^{\mathrm{b}}$ & 0.349 & 0.044 \\
PD value & 18.42 & 17.63 & 18.40 & 18.31 & 5.809 & 0.681 \\
\hline
\end{tabular}

$4 \quad{ }^{1}$ Data are the means of six replicates.

$5 \quad 2$ The particle size of alfalfa meal was $2500,1000,100$ and $10 \mu \mathrm{m}$, respectively.

$6{ }^{3}$ Values with different superscripts in the same row mean significant difference $(P<0.05)$.

7 


\section{Table 2 (on next page)}

Phyla and genera with different relative abundance in caecum of rabbits fed diets with different particle size of alfalfa meal 


\section{Table 2}

2 Phyla and genera with different relative abundance in caecum of rabbits fed diets with different particle size of 3 alfalfa meal

\begin{tabular}{|c|c|c|c|c|c|c|}
\hline \multirow{2}{*}{ Item $^{1}$} & \multicolumn{4}{|c|}{ Treatments $^{2}$} & \multirow[b]{2}{*}{ SEM } & \multirow[b]{2}{*}{$P$-value ${ }^{3}$} \\
\hline & $2500 \mu \mathrm{m}$ & $1000 \mu \mathrm{m}$ & $100 \mu \mathrm{m}$ & $10 \mu \mathrm{m}$ & & \\
\hline \multicolumn{7}{|l|}{ Bacteria phylum } \\
\hline Proteobacteria & $2.69^{\mathrm{b}}$ & $3.37^{\mathrm{a}}$ & $3.40^{\mathrm{a}}$ & $3.34^{\mathrm{a}}$ & 0.09 & 0.005 \\
\hline Tenericutes & $0.35^{\mathrm{b}}$ & $0.48^{\mathrm{b}}$ & $0.47^{\mathrm{b}}$ & $2.11^{\mathrm{a}}$ & 0.193 & $<0.001$ \\
\hline Cyanobacteria & $0.04^{\mathrm{b}}$ & $0.18^{\mathrm{a}}$ & $0.12^{\mathrm{ab}}$ & $0.16^{\mathrm{a}}$ & 0.019 & 0.042 \\
\hline Fusobacteria & $0.03^{\mathrm{b}}$ & $0.02^{\mathrm{b}}$ & $0.04^{\mathrm{ab}}$ & $0.07^{\mathrm{a}}$ & 0.006 & 0.022 \\
\hline SHA-109 & $0^{\mathrm{b}}$ & $0^{\mathrm{b}}$ & $0^{\mathrm{b}}$ & $0.005^{\mathrm{a}}$ & 0.000 & 0.010 \\
\hline \multicolumn{7}{|l|}{ Bacterial genus } \\
\hline Ruminococcaceae UCG-014 & $13.25^{\mathrm{b}}$ & $9.34^{\mathrm{b}}$ & $11.55^{\mathrm{b}}$ & $33.82^{\mathrm{a}}$ & 2.642 & $<0.001$ \\
\hline Lachnospiraceae NK4A136 group & $10.73^{\mathrm{a}}$ & $8.80^{\mathrm{a}}$ & $9.61^{\mathrm{a}}$ & $2.40^{\mathrm{b}}$ & 1.071 & 0.016 \\
\hline Ruminococcaceae NK4A214 group & $3.13^{\mathrm{ab}}$ & $4.71^{\mathrm{a}}$ & $4.39^{\mathrm{a}}$ & $1.74^{\mathrm{b}}$ & 0.428 & 0.044 \\
\hline Ruminococcaceae UCG-005 & $2.10^{\mathrm{b}}$ & $2.84^{\mathrm{a}}$ & $2.38^{\mathrm{ab}}$ & $1.99^{\mathrm{b}}$ & 0.106 & 0.012 \\
\hline Lactobacillus & $1.55^{\mathrm{b}}$ & $1.99^{\mathrm{a}}$ & $1.90^{\mathrm{a}}$ & $1.87^{\mathrm{a}}$ & 0.06 & 0.043 \\
\hline Christensenellaceae $R-7$ group & $1.68^{\mathrm{ab}}$ & $2.14^{\mathrm{a}}$ & $1.12^{\mathrm{b}}$ & $1.01^{\mathrm{b}}$ & 0.153 & 0.019 \\
\hline Lachnospiraceae other (Family) & $1.89^{\mathrm{a}}$ & $1.27^{\mathrm{ab}}$ & $1.54^{\mathrm{a}}$ & $0.72^{\mathrm{b}}$ & 0.137 & 0.011 \\
\hline Ruminococcaceae UCG-013 & $1.15^{\mathrm{a}}$ & $1.00^{\mathrm{a}}$ & $1.12^{\mathrm{a}}$ & $0.67^{\mathrm{b}}$ & 0.064 & 0.021 \\
\hline Clostridium sensu stricto 1 & $0.69^{\mathrm{b}}$ & $0.91^{\mathrm{a}}$ & $1.00^{\mathrm{a}}$ & $0.83^{\mathrm{ab}}$ & 0.04 & 0.029 \\
\hline Unclassified MollicutesRF9 (Order) & $0.32^{\mathrm{b}}$ & $0.43^{\mathrm{b}}$ & $0.41^{\mathrm{b}}$ & $2.00^{\mathrm{a}}$ & 0.185 & $<0.001$ \\
\hline Succinivibrionaceae UCG-002 & $0.50^{\mathrm{b}}$ & $0.70^{\mathrm{a}}$ & $0.66^{\mathrm{a}}$ & $0.72^{\mathrm{a}}$ & 0.029 & 0.02 \\
\hline Ruminiclostridium 9 & $0.45^{\mathrm{ab}}$ & $0.74^{\mathrm{a}}$ & $0.27^{\mathrm{b}}$ & $0.19^{\mathrm{b}}$ & 0.064 & 0.004 \\
\hline Ruminobacter & $0.25^{\mathrm{b}}$ & $0.39^{\mathrm{a}}$ & $0.40^{\mathrm{a}}$ & $0.40^{\mathrm{a}}$ & 0.022 & 0.032 \\
\hline Subdoligranulum & $0.29^{\mathrm{a}}$ & $0.28^{\mathrm{a}}$ & $0.28^{\mathrm{a}}$ & $0.18^{\mathrm{b}}$ & 0.017 & 0.044 \\
\hline Unclassified Gastranaerophilales (Order) & $0.03^{\mathrm{b}}$ & $0.14^{\mathrm{a}}$ & $0.08^{\mathrm{ab}}$ & $0.14^{\mathrm{a}}$ & 0.017 & 0.039 \\
\hline Ruminiclostridium 1 & $0.15^{\mathrm{a}}$ & $0.08^{\mathrm{ab}}$ & $0.03^{\mathrm{b}}$ & $0.04^{\mathrm{b}}$ & 0.017 & 0.045 \\
\hline Ruminococcaceae UCG-001 & $0.04^{\mathrm{b}}$ & $0.09^{\mathrm{a}}$ & $0.10^{\mathrm{a}}$ & $0.08^{\mathrm{a}}$ & 0.007 & 0.014 \\
\hline Turicibacter & $0.04^{\mathrm{b}}$ & $0.08^{\mathrm{a}}$ & $0.07^{\mathrm{a}}$ & $0.067^{\mathrm{ab}}$ & 0.005 & 0.024 \\
\hline Akkermansia & $0.16^{\mathrm{a}}$ & $0.03^{\mathrm{b}}$ & $0.03^{\mathrm{b}}$ & $0.01^{\mathrm{b}}$ & 0.021 & 0.029 \\
\hline Desulfovibrio & $0.04^{\mathrm{b}}$ & $0.10^{\mathrm{a}}$ & $0.03^{\mathrm{b}}$ & $0.01^{\mathrm{b}}$ & 0.010 & 0.011 \\
\hline Cetobacterium & $0.03^{\mathrm{b}}$ & $0.02^{b}$ & $0.04^{\mathrm{ab}}$ & $0.07^{\mathrm{a}}$ & 0.006 & 0.022 \\
\hline Lachnospiraceae NK4B4 group & $0.10^{\mathrm{a}}$ & $0.02^{\mathrm{b}}$ & $0.01^{\mathrm{b}}$ & $0.02^{\mathrm{b}}$ & 0.012 & 0.020 \\
\hline
\end{tabular}




\begin{tabular}{lcccccc} 
Comamonadaceae other (Family) & $0.01^{\mathrm{b}}$ & $0.03^{\mathrm{a}}$ & $0.02^{\mathrm{ab}}$ & $0.03^{\mathrm{a}}$ & 0.003 & 0.033 \\
Novosphingobium & $0.01^{\mathrm{b}}$ & $0.03^{\mathrm{a}}$ & $0.02^{\mathrm{ab}}$ & $0.01^{\mathrm{b}}$ & 0.003 & 0.011 \\
Pseudomonas & $0.01^{\mathrm{b}}$ & $0.005^{\mathrm{b}}$ & $0.007^{\mathrm{b}}$ & $0.03^{\mathrm{a}}$ & 0.003 & 0.042 \\
Unclassified Oxalobacteraceae (Family) & $0.01^{\mathrm{b}}$ & $0.03^{\mathrm{a}}$ & $0.01^{\mathrm{b}}$ & $0.01^{\mathrm{b}}$ & 0.003 & 0.007 \\
Aerococcus & $0.02^{\mathrm{a}}$ & $0.004^{\mathrm{b}}$ & $0.01^{\mathrm{b}}$ & $0^{\mathrm{b}}$ & 0.002 & 0.015 \\
Massilia & $0.004^{\mathrm{a}}$ & $0^{\mathrm{b}}$ & $0.004^{\mathrm{a}}$ & $0.02^{\mathrm{a}}$ & 0.002 & 0.030 \\
Mycobacterium & $0.004^{\mathrm{b}}$ & $0^{\mathrm{b}}$ & $0.004^{\mathrm{b}}$ & $0.01^{\mathrm{a}}$ & 0.002 & 0.003 \\
Corynebacterium 1 & $0.002^{\mathrm{b}}$ & $0.004^{\mathrm{ab}}$ & $0.01^{\mathrm{a}}$ & $0.002^{\mathrm{b}}$ & 0.001 & 0.049 \\
Bryobacter & $0^{\mathrm{b}}$ & $0^{\mathrm{b}}$ & $0^{\mathrm{b}}$ & $0.01^{\mathrm{a}}$ & 0.001 & 0.022 \\
Lachnoclostridium 1 & $0^{\mathrm{b}}$ & $0.01^{\mathrm{a}}$ & $0^{\mathrm{b}}$ & $0^{\mathrm{b}}$ & 0.001 & 0.022 \\
Gelria & $0^{\mathrm{b}}$ & $0^{\mathrm{b}}$ & $0^{\mathrm{b}}$ & $0.01^{\mathrm{a}}$ & 0.001 & 0.010 \\
SHA-109 other (Phylum) & $0^{\mathrm{b}}$ & $0^{\mathrm{b}}$ & $0^{\mathrm{b}}$ & $0.01^{\mathrm{a}}$ & 0.001 & 0.010 \\
Archaeal genus & & & & & & \\
Methanobrevibacter & $62.48^{\mathrm{c}}$ & $75.93^{\mathrm{b}}$ & $89.68^{\mathrm{a}}$ & $90.40^{\mathrm{a}}$ & 2.419 & $<0.001$ \\
Methanosphaera & $35.47^{\mathrm{a}}$ & $23.04^{\mathrm{b}}$ & $8.39^{\mathrm{c}}$ & $8.26^{\mathrm{c}}$ & 2.392 & $<0.001$ \\
\hline
\end{tabular}

4 The " 0 " represent not detected;

$5 \quad{ }^{1}$ Data are the means of six replicates;

$6{ }^{2}$ The particle size of alfalfa was $2500,1000,100$ and $10 \mu \mathrm{m}$; data are the average of relative abundance;

$7 \quad{ }^{3}$ Values with different superscripts in the same row mean significant difference $(P<0.05)$. 